\begin{tabular}{ccc}
\hline International Journal of Engineering \& Technology, $7(2.23)(2018) 232-234$ \\
SPC & Website: www.sciencepubco.com/index.php/IJET \\
Research paper & Technology \\
\hline
\end{tabular}

\title{
Load Flow Study of Isolated Hybrid Microgrid for Village Electrification
}

\author{
Kuldip Singh $^{1 *}$, Dr. M. Narendra Kumar ${ }^{2}$, Dr. Satyasis Mishra ${ }^{3}$ \\ ${ }^{1}$ Research Scholar Centurion University, Bhubanesware, Odisha, India \\ ${ }^{2}$ Principal \& Professor, St,Peter's Engineering College, Hyderabad,Telangana,India \\ ${ }^{3}$ Professor, Centurion University, Bhubanesware, Odisha, India \\ *Corresponding author E-mail: ksmann3@gmail.com
}

\begin{abstract}
The government has main concerns to provide the electricity $24 / 7$ for each household in village across the country by 2020 . To fulfill the demand for village electrification renewable energy sources are major focus. The isolated hybrid microgrid is playing the vital role for village electrification solution in India. The major sources for isolated hybrid microgrid are solar, bio-mass and wind energy for village electrification. In isolated microgrid, major challenges are reliability of system to fulfill the electricity demand in village 24/7 from renewable energy sources. In this work, a technical study carried out for load flow study of isolated PV hybrid microgrid for unbalance local distribution network in village. The study carried out by simulation approach with NR iterative method to analyze the unbalance load demand, load flow study, voltage profile, angle, THD\% and power factor of isolated hybrid microgrid.
\end{abstract}

Keywords: Hybrid Isolated Microgrid; Village Electrification; PV; Load Flow; Demand Study; Voltage Profile; Iterative Method;

\section{Introduction}

Driven by economical, clean energy sources and technical incentives, the implementation of PV microgrid for distribution network close to the load is emerging as a complementary infrastructure over the traditional distribution system for village electrification [1]. Solar energy is an essential part of the global agenda for sustainable development for any country, which are struggling with depleting fossil fuel reserves for growing energy demand and impact of climate changes. The government of India also supporting solar power for future demands of electricity in grid connected or OFF grid mode. Solar PV grid has become a promising alternative source for electrical demand in India due to its advantages: abundance, pollution free and renewability [2]. In India many remote villages or communities, do not have interconnection with power grid, due to economic and technical constraints. These villages are managing their daily energy requirements independently mainly from fossil fuels. For improving the life hood in villages, government of India introduce many programs like improvement of health, education, transportation and electricity [3]. The isolated PV microgrid is future step for improving the reliability and quality of the power distribution system in the village. The microgrid is an interconnection with loads and distribution Energy sources such as PV DG or Energy storage system with controllable loads within local electrical boundary, which act as a single controllable unit [3]. For improvement of reliability and quality of local distribution system, the impact of village load, demand response, network losses, voltage profile are the major parameters. The study considering on aggregated load profile in power flow analysis problem. The load flow analysis is an essential tool for the efficient operation and control of isolated Hybrid microgrid [4]. In this paper, we analyze the power flow of isolated microgrid with PV and DG with connected load with Newton Raphson iteration method in SKM tool of sequential power flow program for verifying various distribution parameters of the network. The paper is organized as follows: Section-2 Model of isolated Hybrid microgrid with distribution connection, Section - 3 discuss the load flow solution for isolated Hybrid microgrid, Section-4 present and describe the simulation results, finally in Section5 highlights the main conclusion and contribution of paper.

\section{Model of Isolated Hybrid Microgrid With Distribution Connection}

The Hybrid isolated microgrid consist of PV power plant and Biomass based DG set connected to load via power flow control with common bus as shown in Figure-1.

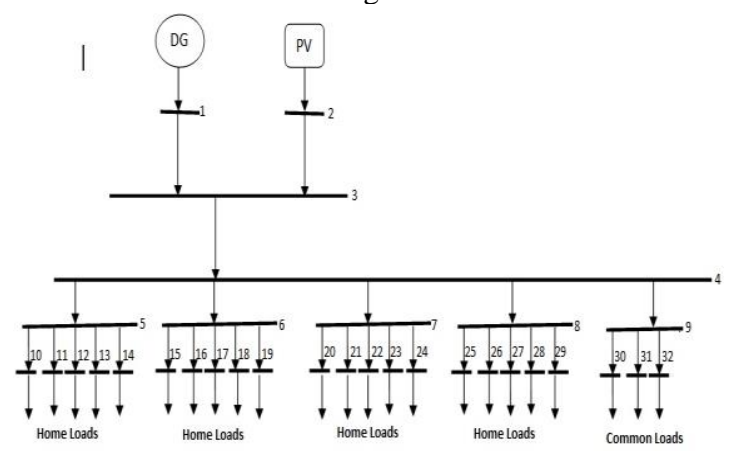

Figure-1 Line diagram of isolated Hybrid microgrid

The balance equations for hybrid isolated microgrid are

$P_{p v}+P_{G}=P_{L}$

Where $P_{p v}$ is power production from solar PV power plant and $P_{G}$ power generation from Bio-mass based DG Set. The $P_{L}$ represented to total load demand which is unidirectional [5]. Total load demand is depends on three phase unbalanced load connected to distribution unit. From distribution unit single phase unbalance 
supply are connected to each household. The three phase unbalance connection for distribution units are shown in Figure-2.

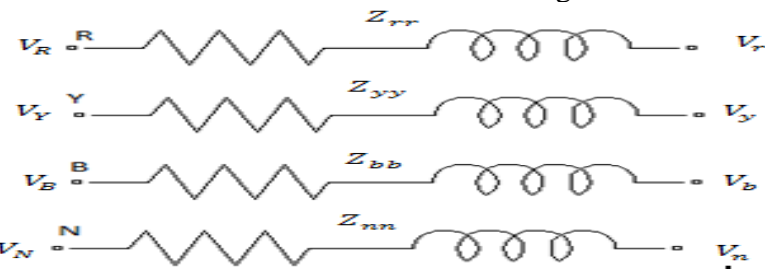

Figure-2 Three phase unbalance line for Distribution

The line parameters for distribution for village electrification can be obtained by method developed by Carson and Lewis. The self and mutual coupling of 3 phase unbalanced distribution line can be expressed as[6]

$\left[Z_{r y b n}\right]=\left[\begin{array}{llll}Z_{r r} & Z_{r y} & Z_{r b} & Z_{r n} \\ Z_{y r} & Z_{y y} & Z_{y b} & Z_{y n} \\ Z_{b r} & Z_{b y} & Z_{b b} & Z_{b n} \\ Z_{n r} & Z_{n y} & Z_{n b} & Z_{n n}\end{array}\right]$

Include the effects of neutral or ground

$$
\left[Z_{r y b}\right]=\left[\begin{array}{lll}
Z_{r r-n} & Z_{r y-n} & Z_{r b-n} \\
Z_{y r-n} & Z_{y y-n} & Z_{y b-n} \\
Z_{b r-n} & Z_{b y-n} & Z_{b b-n}
\end{array}\right]
$$

The relation between voltage and branch current in distribution unit are

$$
\left[\begin{array}{l}
V_{r} \\
V_{y} \\
V_{b}
\end{array}\right]=\left[\begin{array}{l}
V_{R} \\
V_{Y} \\
V_{B}
\end{array}\right]-\left[\begin{array}{lll}
\boldsymbol{Z}_{\boldsymbol{r} \boldsymbol{r}-\boldsymbol{n}} & \boldsymbol{Z}_{\boldsymbol{r y}-\boldsymbol{n}} & \boldsymbol{Z}_{\boldsymbol{r b}-\boldsymbol{n}} \\
\boldsymbol{Z}_{\boldsymbol{y r}-\boldsymbol{n}} & \boldsymbol{Z}_{\boldsymbol{y y}-\boldsymbol{n}} & \boldsymbol{Z}_{\boldsymbol{y b} \boldsymbol{n} \boldsymbol{n}} \\
\boldsymbol{Z}_{\boldsymbol{b r}-\boldsymbol{n}} & \boldsymbol{Z}_{\boldsymbol{b y}-\boldsymbol{n}} & \boldsymbol{Z}_{\boldsymbol{b b}-\boldsymbol{n}}
\end{array}\right]\left[\begin{array}{c}
I_{R r} \\
I_{Y y} \\
I_{B b}
\end{array}\right]
$$

In distribution line any phase failed to present, the corresponding row and column in equation 4 matrix will contain null entries [6].

\section{Load Flow Solution for Isolated Hybrid Mi- crogrid}

Load flow is used to determine the static performance of isolated Hybrid microgrid with distribution system. A load flow study uses simplified notation of distribution system such as one line diagram, voltage drop, load flow current, per unit voltage, power factor, real power and reactive power [7]. The Newton Raphson(NR) Exact iterative method is very well known algorithm for load flow or power flow solution in power system. The NR based power flow algorithms have a common system equation for solving power flow or load flow problem with iterative step. The Generalized minimal residual (GMRES) and Conjugate Gradients (CG) algorithms are implement for solution, where error decreases from one iteration to the next and the exact solution is obtained within a given maximum number of iterations [8].

Consider a system equation

$f(x)=0$

Consider an equation for fixed point iteration method

$x=g(x)$

In equation (6) the fixed point $\boldsymbol{g}$ is a solution of equation (5) Algorithm

1. Start from any point $\boldsymbol{x}_{\mathbf{0}}$

2. Consider the recursive process

$x_{n+1}=g\left(x_{n}\right), n=0,1,2,3 \ldots \ldots$.

3. If $\boldsymbol{f}$ is continuous and $\left(\boldsymbol{x}_{\boldsymbol{n}}\right)$ Converges to some $\boldsymbol{I}_{\mathbf{0}}$

4. Than it is clear that $\boldsymbol{I}_{\mathbf{0}}$ is a fixed point of $\boldsymbol{g}$

5. $\left(\boldsymbol{x}_{\boldsymbol{n}}\right)$ Can be considering as an approximate solution of the equation.

In this paper, the isolated hybrid microgrid has distribution loads and sources, which are assumed to be equivalent injected power in power or load flow analysis. Here $P_{n}^{(k) \text { spec }}$ and $Q_{n}^{(k) s p e c}$ represent

the equivalent active and reactive power injection of the bus and $P_{n}^{(k) c a l}$ and $Q_{n}^{(k) c a l}$ are calculated values of the injected active and reactive power of the bus [9].

The resultant Active Power

$\Delta \boldsymbol{P}_{n}^{(k)}=\boldsymbol{P}_{n}^{(k) s p e c}-P_{n}^{(k) c a l}$

The Reactive Power

$\Delta Q_{n}^{(k)}=Q_{n}^{(k) s p e c}-Q_{n}^{(k) c a l}$

Here $\boldsymbol{P}_{n}^{(k) c a l}=\sum_{i=1}^{n}\left|\boldsymbol{V}_{n}^{(k)}\right|\left|\boldsymbol{V}_{i}^{(k)}\right|\left|\boldsymbol{Y}_{n i}\right| \cos \left(\boldsymbol{\theta}_{n i}+\boldsymbol{\delta}_{i}^{(k)}-\boldsymbol{\delta}_{\circ}^{(k)}\right)$

$Q_{n}^{(k) c a l}=-\sum_{i=1}^{n}\left|V_{n}^{(k)}\right|\left|V_{i}^{(k)}\right|\left|Y_{n i}\right| \sin \left(\theta_{n i}+\delta_{i}^{(k)}-\delta_{o}^{(k)}\right)$

\section{Simulation Results and Discussion}

The loads from village vary their demand for reactive power although they differ widely in their range and rate of variation. The voltage variation is due to the imbalance load demand in the isolated hybrid microgrid. If the generated reactive power is more than demand in distribution system, than voltage levels on each Bus improve. On other hand if the generated reactive power from solar and bio-mass is less than the demand in distribution system, than voltage drop will be more in the Buses [10]. In isolated hybrid microgrid variation in load demand for reactive power causes variation in the voltage drop in each Bus as shown in Table-1.

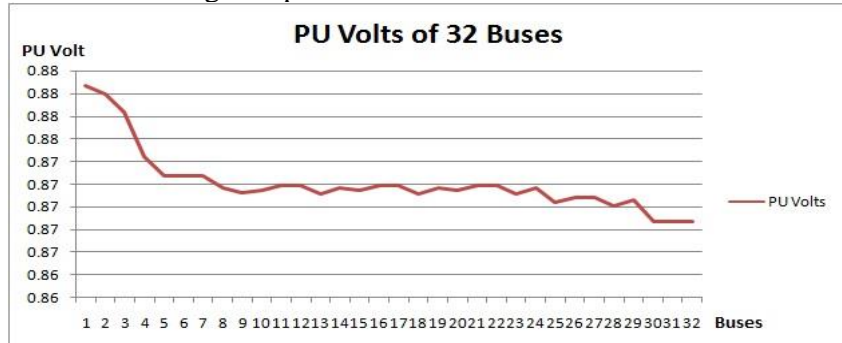

Figure-3 Per Unit voltage on each Bus Bar

Table-1 Load Flow parameters for isolated Hybrid Microgrid

\begin{tabular}{|l|r|r|r|r|r|r|r|}
\hline $\begin{array}{r}\text { From bus } \\
\text { to bus }\end{array}$ & kW Load & kW Loss & kVA load & kVA loss & Pf & LF Amps & THD\% \\
\hline $1->3$ & 158.97 & 0.5 & 197.41 & 0.53 & 0.81 & 316 & 19.84 \\
\hline $2->>3$ & 118.42 & 0.23 & 148.39 & 0.27 & 0.81 & 237 & 19.86 \\
\hline $3->4$ & 276.66 & 1.54 & 345.02 & 1.64 & 0.81 & 553 & 19.85 \\
\hline $4->5$ & 62.26 & 0.15 & 77.74 & 0.16 & 0.80 & 125 & 61.86 \\
\hline $4-->6$ & 62.26 & 0.15 & 77.74 & 0.16 & 0.80 & 125 & 0 \\
\hline $4-->7$ & 62.26 & 0.15 & 77.74 & 0.16 & 0.80 & 125 & 0 \\
\hline $4->>8$ & 62.35 & 0.24 & 77.84 & 0.25 & 0.80 & 125 & 25.94 \\
\hline $4->9$ & 25.99 & 0.13 & 32.39 & 0.13 & 0.80 & 52 & 0.65 \\
\hline $5->10$ & 10.02 & 0.02 & 12.52 & 0.02 & 0.80 & 20 & 61.86 \\
\hline $5->11$ & 15.02 & 0.02 & 18.77 & 0.02 & 0.80 & 30 & 61.86 \\
\hline $5->12$ & 16.02 & 0.02 & 20.02 & 0.02 & 0.80 & 32 & 61.86 \\
\hline $5->13$ & 8.02 & 0.02 & 10.02 & 0.02 & 0.80 & 16 & 61.86 \\
\hline $5->14$ & 13.02 & 0.02 & 16.27 & 0.02 & 0.80 & 26 & 61.86 \\
\hline $6->15$ & 13.02 & 0.02 & 16.27 & 0.02 & 0.80 & 20 & 0 \\
\hline $6->16$ & 10.02 & 0.02 & 12.52 & 0.02 & 0.80 & 30 & 0 \\
\hline $6->17$ & 15.02 & 0.02 & 18.77 & 0.02 & 0.80 & 32 & 0 \\
\hline $6->18$ & 16.02 & 0.02 & 20.02 & 0.02 & 0.80 & 16 & 0 \\
\hline $6->19$ & 8.02 & 0.02 & 10.02 & 0.02 & 0.80 & 26 & 0 \\
\hline $7-->20$ & 10.02 & 0.02 & 12.52 & 0.02 & 0.80 & 20 & 0 \\
\hline $7-->21$ & 15.02 & 0.02 & 18.77 & 0.02 & 0.80 & 30 & 0 \\
\hline $7->22$ & 16.02 & 0.02 & 20.02 & 0.02 & 0.80 & 32 & 0 \\
\hline $7->23$ & 8.02 & 0.02 & 10.02 & 0.02 & 0.80 & 16 & 0 \\
\hline $7->24$ & 13.02 & 0.02 & 16.27 & 0.02 & 0.80 & 26 & 0 \\
\hline $8->25$ & 10.02 & 0.02 & 12.52 & 0.02 & 0.80 & 20 & 61.86 \\
\hline $8->26$ & 15.02 & 0.02 & 18.77 & 0.02 & 0.80 & 30 & 0 \\
\hline $8-->27$ & 16.02 & 0.02 & 20.02 & 0.02 & 0.80 & 32 & 61.86 \\
\hline $8-->28$ & 8.02 & 0.02 & 10.02 & 0.02 & 0.80 & 16 & 0 \\
\hline $8->>29$ & 13.02 & 0.02 & 16.27 & 0.02 & 0.80 & 26 & 0 \\
\hline $9->30$ & 8.62 & 0.04 & 10.76 & 0.04 & 0.80 & 17 & 0.65 \\
\hline $9->31$ & 8.62 & 0.04 & 10.76 & 0.04 & 0.80 & 17 & 0.65 \\
\hline $9->32$ & 8.62 & 0.04 & 10.76 & 0.04 & 0.80 & 17 & 0.65 \\
\hline & & & & & & & \\
\hline
\end{tabular}


In this paper NR iteration Method was applied to solve the load flow of the isolated hybrid microgrid for village electrification, which contain solar (PV) power plant and bio-mass based DG genset as an energy sources for fulfill the demand of electricity $24 / 7$ in the village. The three phase unbalanced supply is distributed to village, each household connect single phase supply and common loads of village like water supply are connected to three phase supply. The load flow or power flow analysis conduct in SKM simulation too for per unit voltage as shown in Figure-3, voltage drop as shown in Figure-4, Angle degree as shown in figure-5 and fault current SLG \& LL as shown in Figure-6 \& Figure-7 THD \% at each Bus in 32 buses distribution system.

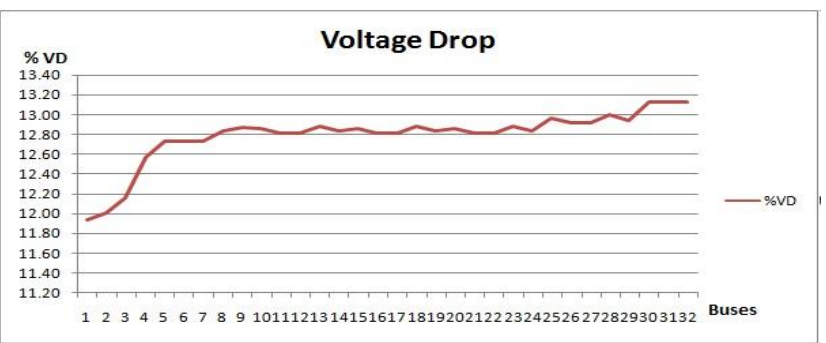

Figure-4 Voltage Drop on each Bus

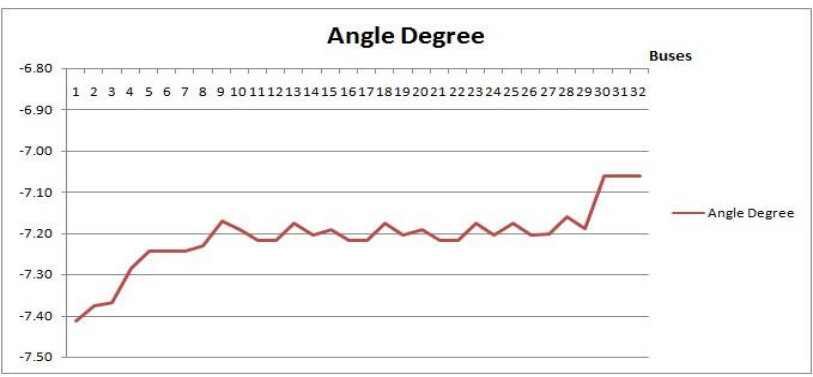

Figure-5 Angle Degree on each Bus

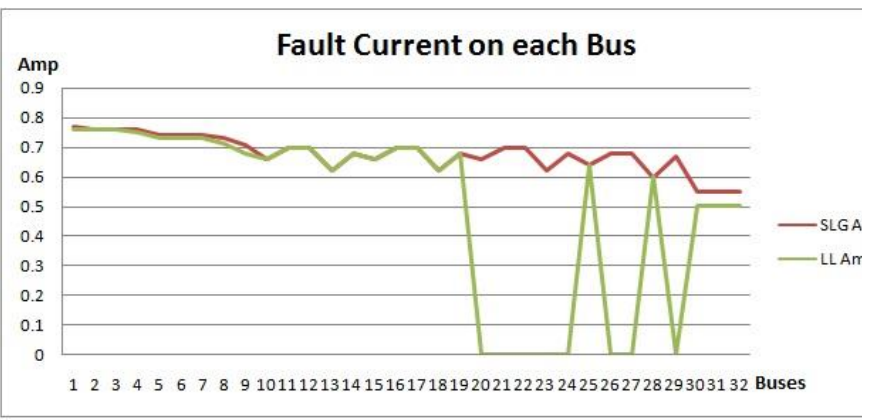

Figure-6 Fault Current on each Bus

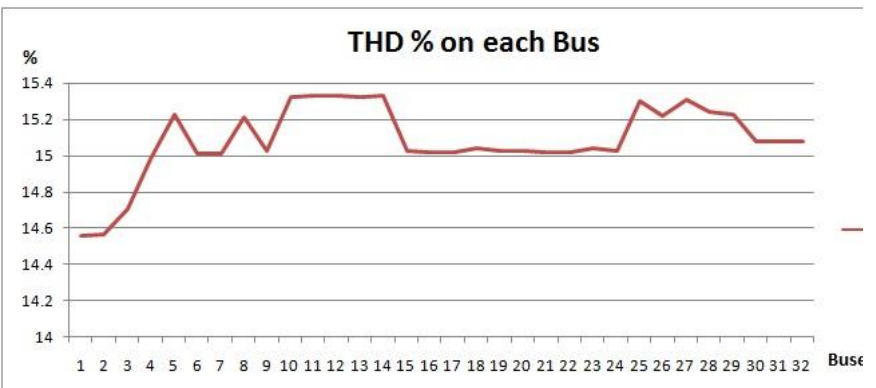

Figure-7 THD \% on each bus

\section{Conclusion}

The load flow analysis for isolated hybrid microgrid carry out with NR iteration Method for radial distribution Network for village electrification with SKM tool. By using the iteration method voltage drop, voltage magnitude, losses on each bus are calculated. The iteration method has fast coverage ability. The results for 32 Buses have been tabulated and shown in figures. It was found that isolated hybrid microgrid is suitable for village electrification to fulfill the electric demand in 24/7 from the non- convention energy sources.

\section{References}

[1] Mohamed Zakaria Kamh, Reza Iravani, “ Unbalanced Model and Power- Flow Analysis of Microgrids and Active Distribution Systems", IEEE Transactions on Power Delivery, Vol.25,No.4 October 2010, pp 2851-2858

[2] Sandip Ravi Kumar, Francisco Gafaro, Andrew Daka, Atual Raturi, "Modelling and analysis of grid integration for high share of solar PV in small isolated systems- A case of Kiribati”, Elsevier Renewable Energy 108 March 2017 pp 589-597.

[3] Bharatkumar V. Solanki, Akash Raghurajan, Kankar Bhattacharya and A. Canizares, " Including Smart Loads for optimal demand response in Integrated Energy Management System for Isolated Microgrids", IEEE Transactions on Smart Grid, Vol.8 No.4 July 2017, pp1739-1748

[4] Rabih A.Jabr, " Radial distribution Load Flow Using conic Programming", IEEE Transactions on Power Systems Vol.21, No.3 August 2006,pp1458-1459

[5] Marko Gulin, Mario Vasak and Mato Baotic, "Analysis of Microgrid Power flow optimization with consideration of residual storage state", European Control Conference (ECC), Linz, Austria 2015, 15-17 July 2015 pp $3126-3131$

[6] Jen-Hao Teng "A direct approach for distribution system Load flow solutions", IEEE Transactions on Power Delivery, Vol.18,No.3 July 2003, pp 882-887

[7] J.A.Michline Rupa, S. Ganesh "Power Flow analysis for radial distribution system using Backward/Forward Sweep Method", International Journal of Electrical, computer, Energetic, Electronics and Communication Engineering Vol.8, No.10, 2014 pp16211625

[8] Rainer Bacher, Eric Bullinger "Application of Non- stationary Iterative methods to an exact Newton Raphson solution process for Power Flow equations", Proc. Power system computations conference, August 19-23, 1996, Dresden Germany, pp453-459.

[9]. Wei-Tzer Huang and Wen-chih Yang, "Power Flow analysis of a grid connected high voltage Microgrid with various distributed resources" 2011 Second International Conference on Mechanic Automation and Control Engineering (MACE), 15-17 July 2011 Hohhot, China Page(s):1471 - 1474

[10] S. Sivanagaraju \& G. Sreenivasan, "Power system operation and control", A text book by Peason, Ninth impression 2013

[11] Kuldip Singh, Satyasis Mishra, M. Narendra Kumar “A Review on Power Management and Power Quality for Islanded PV Microgrid in Smart Village", Indian Journal of Science and Technology, Vol(10) May 2017 pp 1-4 